\title{
MENINGOENCEFALITE NA FASE AGUDA DO SARAMPO \\ RELATO DE SEIS CASOS
}

\author{
FABIANE EL-FAR*, JAQUES SZTAJNBOK**, PAULO C. F. MAROTTO**, ANTONIO C. SEGURO***
}

\begin{abstract}
RESUMO - Apresentamos 6 casos de meningoencefalite aguda por sarampo, diagnosticados durante epidemia na cidade de São Paulo, em 1997. Os prontuários dos 6 pacientes foram analisados retrospectivamente. O diagnóstico de meningoencefalite baseou-se nas alterações clínicas e liquóricas, e foi confirmado por sorologia específica. Dos 467 pacientes com sarampo atendidos no Instituto de Infectologia Emílio Ribas nesse período, estes 6 evoluíram com alterações neurológicas e liquóricas durante a fase exantemática, sendo a sonolência e rigidez de nuca os achados mais frequentes. Os pacientes tinham entre 2 meses e 28 anos de idade. O exame do líquor mostrou pleocitose em todos. Não houve correlação entre a severidade do quadro clínico e liquórico com a evolução. Em 4 casos foi necessária internação na unidade de terapia intensiva; destes, 2 foram intubados. Apenas 2 pacientes apresentaram alterações na tomografia computadorizada de crânio. Todos tiveram boa evolução, sem sequelas.
\end{abstract}

PALAVRAS-CHAVE: sarampo, meningoencefalite, encefalite, meningite.

\section{Acute meningoencephalitis due to measles: report of six cases}

ABSTRACT - We present the clinical and laboratory manifestations of encephalitis following measles in six patients which were diagnosed during the epidemics that occurred in the city of São Paulo, Brazil, in 1997. We performed retrospective case analysis of the six patients diagnosed as having encephalitis due to measles. Encephalitis was diagnosed based on clinical grounds and on the cerebrospinal fluid (CSF) alterations. All the cases were serologically confirmed.Of 467 patients with measles who presented themselves for medical care at the Instituto de Infectologia Emílio Ribas six were diagnosed with encephalitis. Patient's age was 2 months to 28 years old. The most frequent symptoms were drowsiness and nuchal rigidity. CSF showed an increased of white cell count in all cases. Four patients were admitted to the intensive care unit. Two of them required mechanical ventilation. In only two patients did the computerized tomography show abnormalities. All showed good recovery without sequelae.

KEY WORDS: measles, meningoencephalitis, encephalitis, meningitis.

A meningoencefalite aguda do sarampo, também referida como encefalite perivenosa, foi descrita pela primeira vez em 1790 por Lucas ${ }^{1}$, sendo considerada a complicação neurológica mais frequente no sarampo, seguida da encefalite subaguda e da panencefalite esclerosante subaguda ${ }^{1,2}$. Caracterizada por desmielinização multifocal aguda, pode também ser encontrada associada a outras doenças de etiologia viral e autoimune ${ }^{2-4}$. Sua incidência é considerada baixa (1/1000 casos de sarampo), com mortalidade de aproximadamente 10 a $20 \%$. A maioria dos sobreviventes apresenta sequelas s.,25-7. $^{1}$.

Em 1997, uma epidemia de sarampo eclodiu no Estado de São Paulo com 57625 casos suspeitos notificados dos quais 20950 confirmados com sorologia específica para sarampo. Neste período, 697 casos suspeitos foram atendidos no Instituto de Infectologia Emílio Ribas, dos quais 467 confirmados.

Unidade de Terapia Intensiva (UTI) do Instituto de Infectologia Emílio Ribas (IIER), São Paulo - Brasil: *Médica Infectologista do IIER; **Médico Assistente da UTI do IIER; ***Professor Livre Docente da Faculdade de Medicina da Universidade de São Paulo. Médico Supervisor da UTI do IIER. Aceite: 4-novembro-1999.

Dra. Fabiane El-Far - Al. Sarutaiá 136 / 84 - 01403-010 São Paulo SP - Brasil. E-mail: fabfar@ hotmail.com 
Descrevemos o quadro clínico, laboratorial e evolutivo de 6 pacientes admitidos neste período com comprometimento encefalítico agudo por sarampo.

\section{RELATO DOS CASOS}

Caso 1. Paciente do sexo masculino, 26 anos, negro, admitido com quadro de cefaléia holocraniana e febre não medida há 7 dias, acompanhada de rinorréia hialina, com história de há 1 dia exantema máculo papular morbiliforme difuso. Exame físico: paciente em regular estado geral, consciente, confuso, afebril, eupneico, com hiperemia conjuntival, placas de Koplik na cavidade oral, exantema máculo-papular difuso, rigidez de nuca e marcha atáxica cerebelar. FC: $88 \mathrm{bpm}$, FR: $20 \mathrm{mrm}$, PA: 120X80 mmHg. Exames laboratoriais (Tabela 1). Tomografia computadorizada (TC) de crânio: normal. Evolução: afebril, com melhora progressiva do quadro neurológico, tendo tido alta após 4 dias com remissão completa do quadro. Sorologia específica para sarampo: IgM positivo.

Caso 2. Paciente do sexo masculino, 28 anos, branco, admitido no IIER após transferência de outro hospital com história de febre não medida, rinorréia hialina, hiperemia conjuntival há 6 dias. Dois dias após, exantema máculo papular difuso seguido de torpor e crise convulsiva. Admitido em mau estado geral, sedado, intubado, com exantema máculo-papular difuso e hiperemia conjuntival, apresentando abalos musculares e rigidez de nuca. Foi internado na UTI com hipótese de meningite bacteriana de etiologia indeterminada. Iniciado tratamento com dexametasona e ampicilina. Exames laboratoriais (Tabela 1). TC: normal. Eletrencefalograma (EEG): sofrimento cerebral difuso com ondas sugestivas de foco irritativo no lobo temporal esquerdo. No $2{ }^{\circ}$ dia de internação foi extubado, não apresentando mais crises convulsivas e a antibioticoterapia foi modificada para ceftriaxone e clindamicina por suspeita de broncopneumonia aspirativa. Recebeu alta da UTI no $5^{\circ}$ dia de internação. As sorologias para sífilis, citomegalovirus e enterovirus, assim como as culturas de líquor e sangue, resultaram negativas. Reação imunológica no líquor e a sorologia (IgM) para sarampo foram positivas. Alta hospitalar no $12^{\circ}$ dia de internação com quadro de broncopneumonia em resolução e exame neurológico normal.

Caso 3. Lactente de 1 ano, sexo masculino, branco, admitido com história de há 15 dias tosse seca, acompanhada de febre $\left(38^{\circ} \mathrm{C}\right)$ e há 5 dias exantema máculo-papular difuso, sonolência e paralisia facial à esquerda. Ao exame físico: regular estado geral, sonolento, hipocorado, adenomegalia cervical e occipital de cerca de $1 \mathrm{~cm}$, exantema máculo-papular difuso, estertores subcrepitantes bilaterais difusos, rigidez de nuca e paralisia facial periférica à esquerda. Otoscopia: opacificação da membrana timpânica esquerda, com aumento da vascularização. FR: $42 \mathrm{mrm}$, FC: $160 \mathrm{bpm}$ e peso 9400g. Exames laboratoriais (Tabela 1). RX de tórax: broncopneumonia, EEG e TC sem alterações. Foi internado com hipótese de meningoencefalite viral, sarampo, otite média aguda à esquerda, broncopneumonia e paralisia facial à esquerda. Iniciada corticoterapia e terapia antimicrobiana com amoxacilina. Evoluiu com melhora progressiva do quadro neurológico com alta no $6^{\circ}$ dia de internação. Sorologia (IgM) para sarampo resultou positiva. A paralisia facial regrediu completamente até o retorno ambulatorial, 14 dias após a alta.

Caso 4. Lactente de 2 meses, sexo masculino, branco, portador de cardiopatia congênita cianótica (comunicação interventricular), transferido de outro hospital com história de há 10 dias febre não medida, rinorréia hialina e exantema máculo-papular difuso há 4 dias. Há 1 dia crises convulsivas e torpor. Mãe refere ter tido sarampo há 15 dias. Admitido em mau estado geral, torporoso, cianótico, eupneico, com sopro sistólico panfocal e exantema máculo-papular difuso. Otoscopia e oroscopia: sem alterações. FC: 140 bpm, FR: 44 mrm. Exames laboratoriais (Tabela 1), RX de tórax: normal, TC: edema cerebral difuso. Foi internado na UTI devido rebaixamento do nível de consciência e crise convulsivas de difícil controle, com hipótese de meningoencefalite viral aguda e sarampo. Após 2 dias, com o controle das crises convulsivas, teve alta da UTI. Alta hospitalar no $6^{\circ}$ dia de internação com exame neurológico normal. Sorologia específica para sarampo (IgM), positiva.

Caso 5. Criança de 2 anos, sexo feminino, branca, admitida com febre não medida, conjuntivite, tosse com expectoração amarelada há 6 dias e exantema máculo papular difuso acompanhado de sonolência. Exame físico: regular estado geral, sonolenta, cianótica, taquidispneica, descorada, desidratada, com murmúrio vesicular diminuído em base pulmonar direita e abolido em base esquerda, exantema máculo-papular difuso e lesão pústulo-crostosa com sinais flogísticos no terço proximal da coxa esquerda. FR: $40 \mathrm{mrm}$, FC: $130 \mathrm{bpm}$, peso: 12000 g. Foi internada na UTI com sepsis e instabilidade hemodinamica. Exames laboratoriais (Tabela 1). RX de tórax: pneumonia lobar esquerda. TC: normal. Ecocardiograma: sem alterações. Realizada hemotransfusão e iniciada antibioticoterapia com oxacilina. Recebeu alta da UTI no $5^{\circ}$ dia de internação e alta hospitalar no $17^{\circ}$, com melhora importante do quadro clínico. Sorologia específica para sarampo e reação imunológica no líquor resultou positiva (IgM). 
Caso 6. Paciente de 26 anos, sexo feminino, branca, admitida com rinorréia hialina, febre não medida, cefaléia holocraniana, tosse seca há 5 dias seguida de exantema máculo papular difuso e sonolência. Refere ter tido contato com pessoa com sarampo há 20 dias. Exame físico: mal estado geral, sonolenta, desidratada, com placas de Koplik na cavidade oral, exantema máculo papular difuso e rigidez de nuca. Foi internada na UTI e submetida a ventilação mecânica por rebaixamento do nível de consciência. Exames laboratoriais (Tabela 1). RX de tórax: normal. TC: edema cerebral difuso. Alta da UTI após extubação no $2^{\circ}$ dia de internação, com alta hospitalar no $6^{\circ}$ dia. Hemoculturas e sorologias para enterovirus, toxoplasmose, herpes e citomegalovirus resultaram negativas. Sorologia específica para sarampo (IgM) foi positiva.

\section{DISCUSSÃO}

Dos 697 casos de sarampo que o Instituto de Infectologia Emílio Ribas atendeu no ano de 1997, apenas 127 foram internados, 6 dos quais com meningoencefalite.

Alguns aspectos desta casuística podem ser considerados não usuais, quando comparados com casos publicados na literatura, a saber: a incidência de metade dos casos de meningoencefalite descritos ocorrendo entre crianças com até que dois anos; a evolução benigna favorável de todos os casos e a ausência de sequelas no acompanhamento tardio ${ }^{1,2,7-9}$

A meningoencefalite aguda pós infecciosa por sarampo é rara antes dos 2 anos de idade, com incidência de 1 para cada 1000 casos da doença, mortalidade estimada entre 10 e $20 \%$, podendo alcançar taxas de até $32 \%$, evoluindo com sequelas na maioria dos sobreviventes ${ }^{1,2,5-7}$.

O quadro clínico da encefalite geralmente tem início junto ao período exantemático, variando de 1 a 8 ou 2 a 12 dias conforme relatos de literatura ${ }^{1,2,5,6,8}$. Nos casos estudados este período variou de 0 a 4 dias. As alterações neurológicas mais frequentes foram torpor e rigidez de nuca. Apenas 2 pacientes evoluíram com crises convulsivas, apesar de ser esta descrita como a manifestação clínica mais frequente ${ }^{1,6,9}$. Dois casos evoluíram com quadro exuberante, caracterizado por ataxia cerebelar

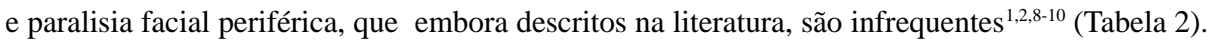

O líquor colhido por ocasião da admissão revelou pleocitose com predomínio linfomononuclear e glicorraquia normal em todos os pacientes; a proteinorraquia estava elevada em 4 casos, em três dos quais acima de $100 \mathrm{mg} / \mathrm{dl}$ (Tabela 1). Estes dados diferem dos apresentados por outros autores $\mathrm{s}^{1,2,5,6}$. Andres e col. em recente epidemia na Espanha, encontrou celularidade e proteinorraquia baixas nos 7 casos estudados. Johnson e col., analisando 31 amostras de líquor de pacientes com

Tabela 1. Exames laboratoriais à admissão.

\begin{tabular}{|c|c|c|c|c|c|c|c|}
\hline \multirow[t]{2}{*}{ Paciente } & \multicolumn{4}{|c|}{ Liquor } & \multicolumn{2}{|l|}{ Hemograma } & \multirow{2}{*}{$\begin{array}{c}\text { TC } \\
\text { Crânio }\end{array}$} \\
\hline & $\begin{array}{l}\text { Células } \\
\mathrm{mm}^{3}(\% \mathrm{~L})\end{array}$ & $\begin{array}{c}\text { Prot } \\
(\mathrm{mg} / \mathrm{dl})\end{array}$ & $\begin{array}{c}\text { Glic } \\
(\mathrm{mg} / \mathrm{dl})\end{array}$ & $\begin{array}{c}\mathrm{Hb} \\
(\mathrm{g} / \mathrm{dl})\end{array}$ & $\begin{array}{l}\text { Leucograma } \\
\text { leucócito/ } \mathrm{mm}^{3} \\
\text { (diferencial) }\end{array}$ & Plaquetas & \\
\hline 1 & $39(80 \% \mathrm{~L})$ & 27 & 63 & 15,0 & $11.400(2 \mathrm{M}, 3 \mathrm{~B}, 80 \mathrm{~S})$ & 363 & normal \\
\hline 2 & 146 (93\% L) & 205 & 117 & 13,5 & $10.900(25 \mathrm{~B}, 50 \mathrm{~S})$ & 221 & normal \\
\hline 3 & $42(43 \% \mathrm{~L})$ & 80 & 63 & 10,0 & $58.000(5 \mathrm{M}, 20 \mathrm{~B}, 67 \mathrm{~S})$ & 549 & normal \\
\hline 4 & $15(78 \% \mathrm{~L})$ & 102 & 64 & 12,9 & $12.700(1 \mathrm{~B}, 32 \mathrm{~S})$ & 274 & edema difuso \\
\hline 5 & $25(98 \% \mathrm{~L})$ & 26 & 49 & 8,6 & $8.600(15 \mathrm{~B}, 63 \mathrm{~S})$ & 205 & normal \\
\hline 6 & $151(62 \% \mathrm{~L})$ & 158 & 62 & 12,8 & $16.800(3 \mathrm{~B}, 62 \mathrm{~S})$ & 297 & edema difuso \\
\hline
\end{tabular}

$\%$ L, percentual de linfócitos; Hb, hemoglobina, contagem diferencial de leucócitos em \%, M (metamielócitos), B (bastonetes), $\mathrm{S}$ (segmentados); contagem de plaquetas: $\mathrm{mm}^{3} \times 10^{3}$. 
Tabela 2. Quadro clínico e evolução.

\begin{tabular}{|c|c|c|c|c|c|c|c|}
\hline Paciente & $\begin{array}{l}\text { Idade/ } \\
\text { sexo }\end{array}$ & $\begin{array}{c}\text { Quadro clínico } \\
\text { neurológico }\end{array}$ & $\begin{array}{l}\text { Tempo de } \\
\text { internação }\end{array}$ & UTI & VM & $\begin{array}{l}\text { Início do } \\
\text { quadro } \\
\text { neurológico }\end{array}$ & $\begin{array}{c}\text { Infecção } \\
\text { bacteriana } \\
\text { associada }\end{array}$ \\
\hline 1 & $\begin{array}{c}26 \text { anos / } \\
\mathrm{M}\end{array}$ & $\begin{array}{l}\text { ataxia cerebelar, } \\
\text { rigidez de } \\
\text { nuca, cefaleia }\end{array}$ & 4 dias & não & não & $\begin{array}{c}1^{\circ} \text { dia de } \\
\text { rash cutâneo }\end{array}$ & não \\
\hline 2 & $\begin{array}{c}28 \text { anos / } \\
\mathrm{M}\end{array}$ & $\begin{array}{c}\text { torpor, rigidez } \\
\text { de nuca, convulsão }\end{array}$ & 12 dias & 2 dias & 2dias & $\begin{array}{l}1^{\circ} \text { dia de } \\
\text { rash cutâneo }\end{array}$ & $\begin{array}{c}\mathrm{BCP} \\
\text { aspirativa }\end{array}$ \\
\hline 3 & $\begin{array}{c}1 \text { ano / } \\
\mathrm{M}\end{array}$ & $\begin{array}{l}\text { paralisia facial } \\
\text { periférica à E, } \\
\text { torpor, rigidez } \\
\text { de nuca }\end{array}$ & 6 dias & não & não & $\begin{array}{c}4^{\circ} \text { dia de } \\
\text { rash cutâneo }\end{array}$ & $\begin{array}{l}\text { OMA } \\
\text { BCP }\end{array}$ \\
\hline 4 & $\begin{array}{c}2 \text { meses / } \\
\mathrm{M}\end{array}$ & torpor, convulsão & 6 dias & 2 dias & não & $\begin{array}{c}3^{\circ} \text { dia de } \\
\text { rash cutâneo }\end{array}$ & não \\
\hline 5 & $\begin{array}{c}2 \operatorname{anos} / \\
\mathrm{F}\end{array}$ & torpor & 17 dias & 5 dias & não & $\begin{array}{c}1^{\text {o dia de }} \\
\text { rash cutâneo }\end{array}$ & $\begin{array}{l}\text { Pneumonia } \\
\text { lobar esquerda }\end{array}$ \\
\hline 6 & $\begin{array}{c}25 \text { anos / } \\
\mathrm{F}\end{array}$ & $\begin{array}{l}\text { torpor, rigidez } \\
\text { de nuca }\end{array}$ & 6 dias & 3 dias & $1 \mathrm{dia}$ & $\begin{array}{l}4^{\circ} \text { dia de } \\
\text { rash cutâneo }\end{array}$ & não \\
\hline
\end{tabular}

M, masculino; F, feminino; UTI, (unidade de terapia intensiva) - tempo de permanência; VM, (ventilação mecânica) - tempo de intubação; BCP, broncopneumonia; OMA, otite média aguda.

meningoencefalite por sarampo, encontraram apenas 4 com celularidade maior que $100 / \mathrm{mm}^{3}$ e 3 com proteinorraquia maior que $100 \mathrm{mg} / \mathrm{dl}^{2}$. Não houve nestes estudos correlação entre a magnitude das alterações liquoricas e a evolução clínica, fato que também pudemos constatar em nossos casos ${ }^{1,2,9}$.

O hemograma mostrou leucocitose com desvio à esquerda. Não houve alterações bioquímicas séricas significativas (Tabela 1). Em todos os pacientes o diagnóstico foi confirmado laboratorialmente. As amostras de sangue e líquor foram encaminhadas para o Instituto Adolfo Lutz e submetidas ao teste ELISA (enzyme-linked immunosorbent assay) IgM para sarampo (Diagnostic GmbH, Behring, Marburg, Germany).

Dois pacientes apresentaram edema cerebral difuso na TC, porém sem diferenças significativas na evolução clínica quando comparados aos demais casos. Comprometendo preferencialmente a substancia branca cerebral e/ou cerebelar ${ }^{3,4}$, a encefalomielite aguda disseminada, não é habitualmente visualizada na TC de crânio, sendo a ressonância nuclear magnética o exame de escolha para diagnosticar tais lesões ${ }^{3,4,11}$.

Necessitaram de internação em unidade de cuidados intensivos (UTI) 4 dos 6 pacientes estudados, dois dos quais foram intubados por 1 e 2 dias devido a rebaixamento do nível de consciência. A média de dias de internação no hospital foi 8,5 (4-17 dias).

Frequentemente a meningoencefalite por sarampo ocorre entre os não imunizados, podendo ocorrer também entre os que receberam a vacina, porém em incidência abaixo da esperada, 0.3/1000 casos de sarampo ${ }^{5}$. Em nenhum dos 6 casos foi possível comprovar vacinação prévia.

Por ser o sarampo uma doença altamente contagiosa, considera-se adequada uma cobertura vacinal de $94-97 \%$ da população, sendo que até $5 \%$ dos vacinados não desenvolvem imunidade ao vírus. Devido à falha vacinal primária e ao fluxo migratório de pessoas que habitam regiões de baixa cobertura vacinal, houve acúmulo de suscetíveis no Estado de São Paulo, o que facilitou a circulação 
viral. Segundo dados do Centro de Vigilância Epidemiológica de São Paulo "Prof. Alexandre Vranjac", depois de 1992 houve importante acúmulo de suscetíveis na faixa etária abaixo de 5 anos alcançando mais de $20 \%$ desta população o que facilitou a circulação viral e consequente epidemia.

O sarampo continua sendo doença prevalente em nosso meio. A vacinação, que pode conferir uma proteção de até $98 \%$, faz parte do calendário vacinal no Estado de São Paulo desde a década de 70, e ainda é o melhor método preventivo contra esta doença, de suas complicações e de suas sequelas.

\section{REFERÊNCIAS}

1. Miller HG, Stanton JB, Gibbons JL. Parainfectious encephalomyelitis and related syndromes: a critical review of the neurologic complications of the specific fevers. Q J Med 1956;25:427-505.

2. Johnson RT, Griffin DE, Hirsch RL, et al.. Measles encephalomyelitis: clinical and imunologic studies. N Engl J Med 1984;310:137-141.

3. Sztajnbok J, Lignani-Jr L, Bresolin AU, Marotto PCF, Seguro AC. Acute disseminated encephalomyelitis: An unusual cause of encephalitic syndrome in childhood. Pediatr Emerg Care 1998;14:36-38.

4. Whiteman MLH, Bowen BC, Post MID, Bell MD. Intracranial infection. In Atlas SW. Magnetic resonance imaging of the brain and spine. 2Ed. Philadelphia, Lippincott - Raven, 1996:725.

5. Andrés CB, Martín Fdel C, López MLV, Hortelano JG. Encefalitis por sarampión. An Esp Pediatr 1996;45:511-513.

6. Boccetta AC, Tornay AS. Measles encephalitis: report of 61 cases. Am J Dis Child 1964;107:247-255.

7. Ford FR. The nervous complications of measles. Bull Johns Hopkins Hosp 1928;43:140.

8. Hamilton PM, Hanna RJ. Encephalitis complicating measles: a report on two hundred and forty-one cases collected from the literature and on forty-four additional cases. Am J Dis Child 1941;61:483-493.

9. Litvak AM, Sands IJ, Gibel H. Encephalitis complicating measles: report of fifty-six cases with follow-up studies in thirtytwo. Am J Dis Child 1943;65:265- 295.

10. Sharma U, Sasensa S, Desa K.. Measles encephalitis: a clinical study of 25 cases. Indian J Pediatr 1975;42:101-105.

11. Griffin DE. Measles. In Scheld WM, Whitley RJ, Durack DT (eds). Infections of the central nervous system. 2Ed. Philadelphia: Lippincott - Raven, 1997:47-57. 